\title{
EQUIDADE, JUSTIÇA SOCIAL E CULTURA DE PAZ EM TEMPOS DE PANDEMIA: UM OLHAR SOBRE A VULNERABILIDADE MUNICIPAL E A COVID-19
}

\section{EQUITY, SOCIAL JUSTICE AND CULTURE OF PEACE IN PANDEMIC TIMES: A LOOK AT MUNICIPAL VULNERABILITY AND COVID-19}

\author{
Eunir Augusto Reis Gonzaga \\ Doutorando em Geografia. Instituto de Geografia \\ Universidade Federal de Uberlândia \\ eunir@ufu.br \\ Isabella do Carmo Lacerda \\ Graduanda em Engenharia Ambiental \\ Universidade Federal de Uberlândia \\ isabellalacerda@ufu.br \\ Tuila Tachikawa de Jesus \\ Graduanda em Jornalismo \\ Universidade Federal de Uberlândia \\ tuila.jesus@ufu.br \\ Samuel do Carmo Lima \\ Doutor em Geografia. Instituto de Geografia \\ Universidade Federal de Uberlândia \\ samuel@ufu.br
}

\begin{abstract}
RESUMO
Quando surge um novo vírus, com potencial pandêmico, comumente ocorre a partir do contato dos seres humanos com animais silvestres portadores. Nestes casos, o organismo humano não possui mecanismos para combater essa nova infecção, por não ter imunidade natural. Assim, devido à possibilidade de uma alta taxa de transmissão, pesquisadores em todo o mundo buscam estratégias que sejam eficazes contra quaisquer vírus da gripe. Neste artigo, o olhar científico foi direcionado à gestão pública municipal, sendo pertinente compreender de que forma as cidades minimizam a vulnerabilidade das pessoas em seus territórios e, a partir de suas ações, compreender como as medidas tomadas pelo poder público estão contribuindo para o enfrentamento da pandemia gerada pela doença Covid-19. Realizou-se, portanto, um estudo sobre o plano de contingenciamento brasileiro para infecção humana pelo novo coronavírus e, a partir deste, buscou-se compreender quais medidas podem contribuir para a equidade, a justiça social e a cultura de paz. O estudo buscou demonstrar que a adoção de indicadores de sustentabilidade no planejamento pode ser uma forma capaz de minimizar a vulnerabilidade das pessoas e dos lugares, no entanto as cidades brasileiras evidenciaram suas fragilidades, devido aos desafios impostos pela gestão territorial em países em desenvolvimento. Ainda é preciso avançar nas discussões e evidências. Até o momento, o que se sabe é que o distanciamento social é a única forma de evitar o contágio e ser capaz de achatar a curva de contaminação.
\end{abstract}

Palavras-chave: Covid-19. Planejamento Urbano. Sustentabilidade. Vulnerabilidade.

\begin{abstract}
When a new potential pandemic virus appears, it commonly occurs from human contact with wild animals that carries it. In these cases, the human organism, having no natural immunity, has no mechanisms to fight this new infection. So, due to the possibility of a high transmission rate, researchers around the world are looking for strategies that are effective against any flu virus. In this article, the scientific perspective is on municipal public management. It is pertinent to understand how cities minimize
\end{abstract}

Recebido em: 10/05/2020

Aceito para publicação em: 21/05/2020. 
the vulnerability of people in their territories and through their actions and understand how the measures taken by public authorities are contributing to combating Covid-19 disease pandemic. Therefore, a study was carried out on Brazilian contingency plan for human infection with the new coronavirus and, based on this, we sought to understand which measures can contribute to equity, social justice and culture of peace. The study sought to demonstrate that the adoption of sustainability indicators in planning can be a way to minimize the vulnerability of people and places, however Brazilian cities have shown their weaknesses, due to the challenges imposed by territorial management in developing countries. However, further discussions and evidence are still needed. So far, what is known is that social distance is the only way to avoid contagion and to be able to flatten the contamination curve.

Keywords: Covid-19. Sustainability. Urban planning. Vulnerability.

\section{INTRODUÇÃO}

O mundo inteiro iniciou o ano de 2020 estupefato com o surto do novo coronavírus (Sars-CoV-2) que atingia Wuhan, na província de Hubei, na China. Logo, o surto se transformou em epidemia. Em 11/03 a Organização Mundial de Saúde (OMS) declarou pandemia de Covid-19, porque o número de infectados pelo novo coronavírus e o número de mortes por Covid-19 já tinha atingido a maioria dos países do mundo.

Em 10/05/2020, já haviam mais de 4 milhões de pessoas infectadas em todo o mundo, com mais de 280 mil mortes por Covid-19. Nesta data, os países mais afetados eram os EUA com 1.357.062 pessoas infectadas e 80.272 mortes, Reino Unido com 219.183 pessoas infectadas e 31.855 mortes, Itália com 219.070 infectados e 30.560 mortes e França com 174.758 pessoas infectadas e 26.380 mortes (TRADINGVIEW, 2020).

O Brasil, que entrou na pandemia com atraso e ainda tem a curva de transmissão da Covid-19 em forte ascensão já tem 11.123 mortes e 162.699 casos de Covid-19 confirmados (BRASIL, 2020).

O novo coronavírus é de uma família de vírus que já é conhecida deste os anos de 1960, que provoca doenças respiratórias semelhantes à uma gripe ou resfriado comum. Entretanto, alguns coronavírus podem causar doenças mais graves, como a Síndrome Respiratória Aguda Grave (SRAG), que também são causados pelos vírus Influenza A e B, Vírus Sincicial Respiratório, Adenovírus, Parainfluenza e o Metapneumovírus (AMAZONAS, 2020).

O novo coronavirus tem alta transmissibilidade. Os principais sintomas do novo coronavirus nos pacientes são tosse, febre, cansaço e dificuldade para respirar (em casos graves) e, nestes casos, podendo produzir como a Síndrome Respiratória Aguda Grave (SRAG), com alta letalidade. Não há vacina e não há remédio para tratar essa doença. Neste caso, a única coisa que pode reduzir e achatar a transmissão é o isolamento social, junto com medidas de proteção individual como higiene das mãos e uso de máscaras.

A covid-19 no Brasil viajou de avião, vindo da Itália, chegando em São Paulo e nas principais capitais do país com intensa conexão internacional. Primeiramente se difundiu entre os ricos e pessoas da classe média para depois chegar às periferias, onde vivem os pobres, em condição de vulnerabilidade social. Nestas cidades já se vê o colapso do sistema de saúde, com a capacidade de leitos hospitalares de UTI esgotada e pacientes morrendo sem assistência. Depois, o novo coronavirus chegou às cidades médias, polos regionais, e vai se difundindo pelas rodovias, para as cidades menores.

No Brasil, sem comando efetivo do Ministério da Saúde para enfrentar o caos da saúde pública, os Estados e Municípios assumem o protagonismo na luta contra a pandemia, com medidas para melhor organizar o sistema hospitalar, ampliando o número de leitos de UTI, e ao mesmo tempo, determinando isolamento social mais restritivos ou menos restritivos.

Diante disso, sabendo que a administração municipal das cidades assume um papel importante para enfrentar a pandemia, e partindo desse raciocínio, o objetivo deste trabalho é analisar o papel do 
planejamento urbano das cidades brasileiras no enfrentamento da pandemia de Covid-19, sabendo que

Nenhuma delas apresenta uma satisfatória experiência de integração administrativa, especialmente se considerarmos o tema central de controle sobre o uso e ocupação do solo que está relacionado aos grandes problemas vividos pelas metrópoles: sociais, ambientais, de saneamento, de transportes, de drenagem, de saúde e de segurança (MARICATO, 2011, p. 17).

No escopo deste trabalho, que contempla os critérios de sustentabilidade viáveis para o planejamento municipal, apresentam-se as principais medidas que devem ser adotadas pelas prefeituras para 0 enfrentamento da pandemia gerada pela Covid-19.

O artigo foi dividido em três seções. A primeira seção reflete os riscos e vulnerabilidades contempladas em um planejamento urbano sob a ótica das cidades saudáveis e sustentáveis. A segunda trata de um aramado metodológico, pelo qual se propôs conhecer a Agenda 2030 e seus objetivos, o Programa Cidades Sustentáveis (PCS) e o plano de contingenciamento do Ministério da Saúde (MS). E por último, foram elencados e discutidos os resultados, obtidos a partir da relação dos indicadores de sustentabilidade com as ações e medidas emergenciais. Estas comparações foram executadas no intuito de compreender de que forma o país se posiciona para fazer frente à dispersão do vírus Sars-Cov-2, levando em consideração os critérios de equidade, justiça social e cultura de paz.

\section{METODOLOGIA}

A Agenda 2030 para o Desenvolvimento Sustentável apresenta objetivos e metas que estimulam ações em áreas de importância crucial para a humanidade e para o planeta nos próximos anos (ONU, 2015, p.1). Portanto, é possível compreender que:

As interconexões e a natureza integrada dos Objetivos de Desenvolvimento Sustentável (Figura 1) são de importância crucial para assegurar que o propósito da nova Agenda se concretize. Se realizarmos as nossas ambições em toda a amplitude da Agenda, a vida de todos melhorará sensivelmente e nosso mundo será melhor (ONU, 2015, p.2).

O percurso metodológico adotado para este estudo iniciou-se sob a ótica do PCS, desenvolvido em consonância com os ODS, a partir do planejamento urbano municipal:

O PCS oferece uma plataforma digital que reúne ferramentas que podem contribuir para que governos e sociedade civil promovam o desenvolvimento sustentável nos municípios brasileiros. Criado em conjunto pela Rede Nossa São Paulo, da Rede Social Brasileira por Cidades Justas e Sustentáveis e do Instituto Ethos [...] (GONZAGA; RIBEIRO, 2017, p.201).

Figura 1 - Objetivos de Desenvolvimento Sustentável (ODS) que compõem a Agenda 2030 das Nações Unidas
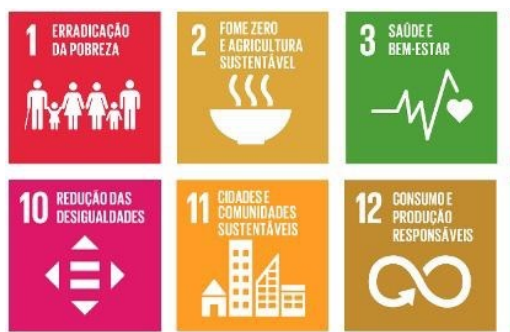
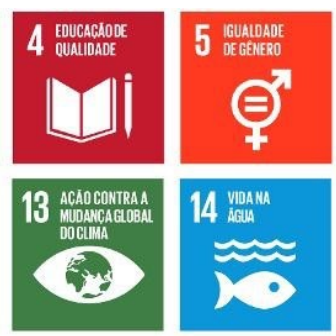

Fonte: ONU (2020, s/p).
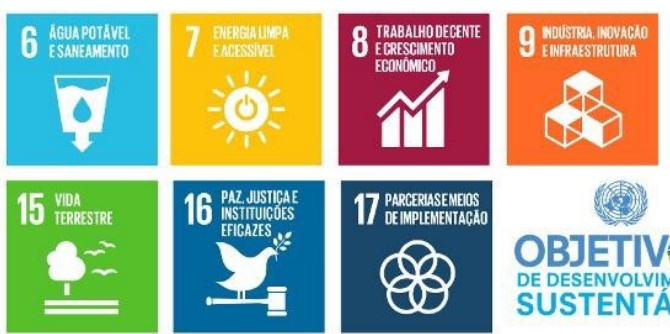

(6)

OBJETIVOS DE DESENVOLVIMENTO 
O PCS é adotado por 217 cidades brasileiras, que assinaram o termo de adesão e se comprometeram a instrumentalizar os indicadores em seu planejamento municipal. Segundo o IBGE (2020, s/p), existem 5.570 municípios em território nacional, localizados nos 26 Estados das cinco Regiões, e também um Distrito Federal, em uma área territorial de 8.510.820,623 quilômetros quadrados.

Seus Eixos Temáticos (Quadro 1) categorizam os indicadores propostos e fazem inferência aos ODS, propostos pela Organização das Nações Unidas (ONU). Foram definidos a partir de um pacto político, assinado no ano de 2004 na cidade dinamarquesa Aalborg, por autoridades de mais de 700 cidades, com o objetivo de fortalecer em nível local as agendas de desenvolvimento.

Esta proposta possibilita diagnosticar o quanto uma gestão pautada em critérios de responsabilidade socioambiental pode estar preparada para o enfrentamento de situações adversas, desde cenários endêmicos e epidêmicos, gerados a partir de arboviroses, por exemplo, até em situações de calamidade pública, que são decretadas pela maior parte dos municípios e distritos do mundo. Neste último cenário, a busca por estratégias para enfrentamento da atual pandemia, causada pela disseminação do vírus Sars-CoV-2, objeto do presente estudo.

Quadro 1 - Eixos Temáticos que compõem o PCS

\begin{tabular}{cl}
\hline Eixo & \multicolumn{1}{c}{ Temática } \\
\hline 1 & Ação Local para a Saúde \\
2 & Bens Naturais Comuns \\
3 & Consumo responsável e opções de estilo de vida \\
4 & Cultura para a sustentabilidade \\
5 & Do Local para o Global \\
6 & Economia Local, Dinâmica, Criativa e Sustentável \\
7 & Educação para a Sustentabilidade e Qualidade de Vida \\
8 & Equidade, Justiça Social e Cultura de Paz \\
9 & Gestão Local para a Sustentabilidade \\
10 & Governança \\
11 & Melhor Mobilidade, Menos Tráfego \\
12 & Planejamento e Desenho Urbano
\end{tabular}

Fonte: PCS (2019, p.06, organizado pelos autores).

A ferramenta metodológica disponível em PCS, $(2017, \mathrm{~s} / \mathrm{p})$ é composta, em seu Eixo Temático "Equidade, Justiça Social e Cultura de Paz", pelos seguintes indicadores: Ações afirmativas para a redução da desigualdade (1); Adolescentes cumprindo medidas socioeducativas (2); Adolescentes envolvidos em ato infracional (3); Afetados por eventos climáticos extremos (4); Agressão a crianças e adolescentes (5); Agressão a idosos (6); Conteúdo relativo aos direitos humanos na formação policial (7); Crianças e adolescentes que sofreram violência sexual (8); Crimes contra a liberdade sexual (9); Crimes sexuais (10); Crimes violentos fatais (11); Denúncias de violação dos direitos humanos (12); Distribuição de renda (13); Domicílios com acesso à internet (14); Domicílios com acesso a telefone celular (15); Famílias inscritas no Cadastro Único para programas sociais (16); Homicídio juvenil (17); Homicídios de mulheres (18); Homicídios na população branca e negra (19); Índice de Desenvolvimento Humano (IDH) municipal (20); Mortes por agressão (21); Mortes por armas de fogo (22); Mulheres jovens de 15 a 24 anos de idade que não estudam nem trabalham (23); Negligência e abandono de crianças e adolescentes (24); Notificações de estupros sofridos por mulheres (25); Notificações de violência contra mulheres e meninas (26); Orçamento para a redução da desigualdade (27); Pessoas com renda de até 1/4 do salário mínimo (28); Política municipal de assistência aos usuários de drogas e dependentes de álcool (29); Políticas habitacionais municipais com critério de gênero (30); Políticas municipais destinadas a ampliar a igualdade socioeconômica (31); População em situação de rua (32); População idosa (33); Quantidade de famílias que recebem o benefício de superação da extrema pobreza (34); Recursos alocados para promoção da igualdade de gênero (35); Renda municipal detida pelos $20 \%$ mais pobres (36); Rendimento médio real por 
gênero (37); Roubos (38); Terras indígenas no município (39); Títulos expedidos às comunidades quilombolas (40); Valor total repassado às famílias beneficiárias do programa bolsa Família (41); Variação da renda domiciliar per capita (42); Wi-fi livre público (43).

Os dados obtidos a partir dos indicadores acima são disponibilizados pelos municípios que aderiram ao programa anualmente, para implementação da Agenda 2030 em nível local. Eles podem conter informações relevantes para a melhor execução de ações necessárias para enfrentamento da doença Covid-19 nos municípios brasileiros.

No mês de janeiro de 2020, em virtude deste enfrentamento, o MS ativou o Centro de Operações de Emergência (COE), coordenado pela Secretaria de Vigilância em Saúde (SVS), para nortear as respostas à possível emergência de saúde pública, para enfrentamento da doença pandêmica. $\mathrm{O}$ COE elaborou o Plano de Contingência Nacional para Infecção Humana pelo novo Coronavírus, especificamente para atender a essa demanda.

\begin{abstract}
O Brasil adota a ferramenta de classificação de emergência em três níveis, seguindo a mesma linha utilizada globalmente na preparação e resposta em todo o mundo. Deste modo, recomenda-se que as Secretarias de Saúde dos Municípios, Estados e Governo Federal, bem como serviços de saúde pública ou privada, agências, empresas tomem nota deste plano na elaboração de seus planos de contingência e medidas de resposta. Toda medida deve ser proporcional e restrita aos riscos vigentes (BRASIL, 2020, p. 4).
\end{abstract}

Este plano é composto por três níveis de resposta: Alerta, que corresponde a uma situação em que o risco de introdução do vírus SarsCoV-2 no país seja elevado, mas não há casos suspeitos; Perigo Iminente, que corresponde a uma situação em que há confirmação de caso suspeito; e Emergência em Saúde Pública, em que há confirmação de transmissão local do primeiro caso no território nacional, ou reconhecimento de declaração de Emergência de Saúde Pública de Importância Internacional (ESPII) pela OMS. Cada nível é baseado na avaliação do risco do novo Coronavírus afetar o Brasil, que a partir do mês de março de 2020, encontra-se no nível de Emergência em Saúde Pública.

Segundo BRASIL (2020, p. 11), as medidas de resposta ao novo coronavírus são categorizadas em: vigilância; suporte laboratorial; medidas de controle de infecção; assistência; assistência farmacêutica; vigilância sanitária; comunicação de risco; e gestão. Para cada nível, há um conjunto de medidas para infecção humana a serem adotadas.

Neste arcabouço instrumental, a análise dos dados buscou compreender quais as medidas do Plano de Contingência Nacional para Infecção Humana pelo novo Coronavírus podem se beneficiar das informações obtidas a partir do indicadores do PCS, relacionados à busca de equidade, justiça social e cultura de paz, justificando a importância da implementação da Agenda 2030 nos municípios, com o propósito de minimizar suas vulnerabilidades.

O trabalho foi desenvolvido integralmente à distância, respeitando as diretrizes de isolamento social definidas pela OMS. Os encontros ocorreram no ambiente virtual da Sala Verde UFU Sustentável, que é o Centro de Educação Ambiental (CEA) da Universidade Federal de Uberlândia (UFU), localizado no Campus Santa Mônica, no município de Uberlândia/MG. Este ambiente, configurado pela plataforma Mconf da Rede Nacional de Ensino e Pesquisa (RNP), junto ao Ministério da Ciência, Tecnologia, Inovações e Comunicações (MCTIC), foi disponibilizado pela Diretoria de Sustentabilidade (DIRSU), a partir de sua Divisão de Planejamento Socioambiental (DIPSA), em parceria com o Centro de Educação à Distância (CEaD), como medida emergencial para manter as atividades desenvolvidas na instituição em formato Home Office, em consonância com o proposto pelo Comitê UFU de Monitoramento à Covid-19 (UFU, 2020, s/p).

Nesta sala virtual, três questionamentos nortearam a discussão entre os autores: a similitude entre a peste negra, a gripe espanhola e o coronavírus; como superar a atual crise de forma menos traumática; e compreender a saúde pública como saúde única.

\title{
RESULTADOS
}

Para estabelecer indicadores de acompanhamento e suporte às tomadas de decisão, utilizou-se o Eixo Temático "Equidade, Justiça Social e Cultura de Paz" do PCS e as diretrizes propostas no Plano de Contingência Nacional para Infecção Humana pelo novo Coronavírus, com vistas a compreender quais ODS (Tabela 1) foram contempladas pela proposta do MS. 
Tabela 1 - Informações e resultados obtidos a partir de cada categoria do plano de contingenciamento

\begin{tabular}{|c|c|c|c|}
\hline $\begin{array}{l}\text { Medidas de } \\
\text { Resposta }\end{array}$ & Ações Relacionadas & PCS & ODS \\
\hline Vigilância & $\begin{array}{l}\text { Comunicação com a OMS; divulgação de normas e diretrizes; } \\
\text { monitoramento de casos suspeitos; serviços de referência; } \\
\text { avaliação de risco; investigação de casos confirmados; boletins } \\
\text { epidemiológicos; rede de vigilância; eventos e rumores nas } \\
\text { mídias digitais; equipes de resposta; rastreamento; materiais de } \\
\text { educação em saúde. }\end{array}$ & $\begin{array}{c}1,12,13,14,15 \\
16,20,32,33 \\
34,35,36,39 \\
43\end{array}$ & $\begin{array}{c}1,9,10,11 \\
16\end{array}$ \\
\hline $\begin{array}{l}\text { Suporte } \\
\text { laboratorial }\end{array}$ & $\begin{array}{l}\text { Diagnósticos laboratoriais; protocolos em consonância com a } \\
\text { OMS; monitorar os resultados laboratoriais; envio das amostras } \\
\text { para laboratórios de referência; diagnósticos laboratoriais RT- } \\
\text { PCR e análises complementares aos Laboratórios de Referência } \\
\text { Nacional e Regionais. }\end{array}$ & $\begin{array}{l}13,15,16,20 \\
27,28,32,33 \\
39,43\end{array}$ & $1,9,10,11$ \\
\hline $\begin{array}{l}\text { Medidas de } \\
\text { controle de } \\
\text { infecção }\end{array}$ & $\begin{array}{l}\text { Orientar os serviços de saúde quanto às medidas de prevenção } \\
\text { e controle de infecção }\end{array}$ & $\begin{array}{c}1,12,13,15,16 \\
20,29,30,31 \\
32,33,39,43\end{array}$ & $\begin{array}{c}1,3,9,10 \\
11,16\end{array}$ \\
\hline Assistência & $\begin{array}{l}\text { Ampliação de leitos; reativação de áreas assistenciais obsoletas, } \\
\text { ou contratação de leitos com isolamento para o atendimento; } \\
\text { orientar as redes de atendimento para UTIs que atendam às } \\
\text { normas de isolamento dos pacientes; reforçar a necessidade de } \\
\text { proteção dos profissionais da área da saúde. }\end{array}$ & $\begin{array}{c}1,2,12,13,15 \\
16,20,23,24 \\
28,29,32,33\end{array}$ & $\begin{array}{c}1,3,5,10 \\
11,16\end{array}$ \\
\hline $\begin{array}{l}\text { Assistência } \\
\text { farmacêutica }\end{array}$ & $\begin{array}{l}\text { Estoque estratégico de medicamentos; informar sobre o fluxo de } \\
\text { serviço farmacêutico; monitorar o estoque de medicamentos no } \\
\text { âmbito federal e estadual; rever e estabelecer logística de } \\
\text { controle, distribuição e remanejamento, conforme solicitação a } \\
\text { demanda. }\end{array}$ & $\begin{array}{c}1,12,13,15,16 \\
20,27,28,32 \\
33\end{array}$ & $\begin{array}{c}1,10,11 \\
16\end{array}$ \\
\hline $\begin{array}{l}\text { Vigilância } \\
\text { Sanitária }\end{array}$ & $\begin{array}{l}\text { Divulgação de material informativo sobre o coronavírus para } \\
\text { viajantes; reforçar orientações para equipes de Aeroportos, } \\
\text { Fronteiras e Recintos Alfandegados sobre medidas de } \\
\text { prevenção e controle, realizando abordagem dos viajantes e } \\
\text { inspeção dos meios de transporte; monitorar os casos suspeitos } \\
\text { e confirmados entre os tripulantes; intensificar os avisos sonoros } \\
\text { nos aeroportos, portos e locais com grande circulação de } \\
\text { passageiros; estabelecer medidas adicionais para aqueles que } \\
\text { apresentam sintomas ou possuem histórico de viagem de locais } \\
\text { com muitos casos da doença. }\end{array}$ & $\begin{array}{c}1,32,33,34,35 \\
36,37,43\end{array}$ & $9,10,11$ \\
\hline $\begin{array}{l}\text { Comunicação de } \\
\text { risco }\end{array}$ & $\begin{array}{l}\text { Emitir orientações de saúde para instituições privadas, escolas e } \\
\text { público em geral; materiais informativos/educativos e distribuí- } \\
\text { los para a população, profissionais de saúde, jornalistas e } \\
\text { formadores de opinião; materiais informativos/educativos } \\
\text { trilíngues para os aeroportos, portos e fronteiras; materiais } \\
\text { informativos para publicidade, redes sociais e também manter } \\
\text { atualizada as páginas sobre o coronavírus; coletivas de } \\
\text { imprensa com representantes e veicular informações que traçem } \\
\text { ações em comum da população governo e mídia; parcerias com } \\
\text { a rede de comunicação pública para emissão de informações } \\
\text { atualizadas. }\end{array}$ & $\begin{array}{c}1,12,13,15,16 \\
20,23,24,25 \\
26,27,28,29 \\
32,33,34,39 \\
43\end{array}$ & $\begin{array}{l}1,3,5,9 \\
10,11,16\end{array}$ \\
\hline
\end{tabular}




\begin{tabular}{|l|l|c|c|}
\hline Gestão & Respostas rápidas para enfrentamento; ampliar horários de & $12,13,15,16$, & $1,3,5,9$, \\
& funcionamento das áreas de saúde; ações integradas entre & $20,23,24,26$, & 10,16 \\
& vigilância em saúde, assistência, e outros órgãos envolvidos no & $27,28,29,30$, & \\
& combate; ações emergenciais no enfrentamento; ações de & $31,34,35,37$, & 39,43 \\
& educação em saúde; apoio aos gestores estaduais no & & \\
& acompanhamento da execução dos Planos de Contingência \\
& para a infecção humana; divulgação de materiais desenvolvidos \\
& pela área técnica. & & \\
\hline
\end{tabular}

Fonte: Organizada pelos autores.

Na gestão pública, os indicadores cumprem um papel fundamental em diversas etapas. Eles ajudam os tomadores de decisão a avaliar adequadamente a realidade, a interpretar os desejos e necessidades da população e a implementar ações que atendam às prioridades estabelecidas (PCS, 2017, s/p). Neste estudo, foram analisados cada um dos indicadores, verificando se diretamente podem minimizar a vulnerabilidade e promover a saúde.

O gráfico contido na Figura 2 exibe o quantitativo de indicadores do Eixo Temático "Equidade, Justiça Social e Cultura para a Paz" do PCS que podem ser utilizados para implementação das medidas emergenciais propostas pelo Plano de Contingência Nacional para Infecção Humana pelo novo Coronavírus, relacionando-os com os ODS da ONU.

Figura 2 - Objetivos da ONU e sua incidência em números absolutos nas diretrizes propostas pelo plano de contingenciamento nacional

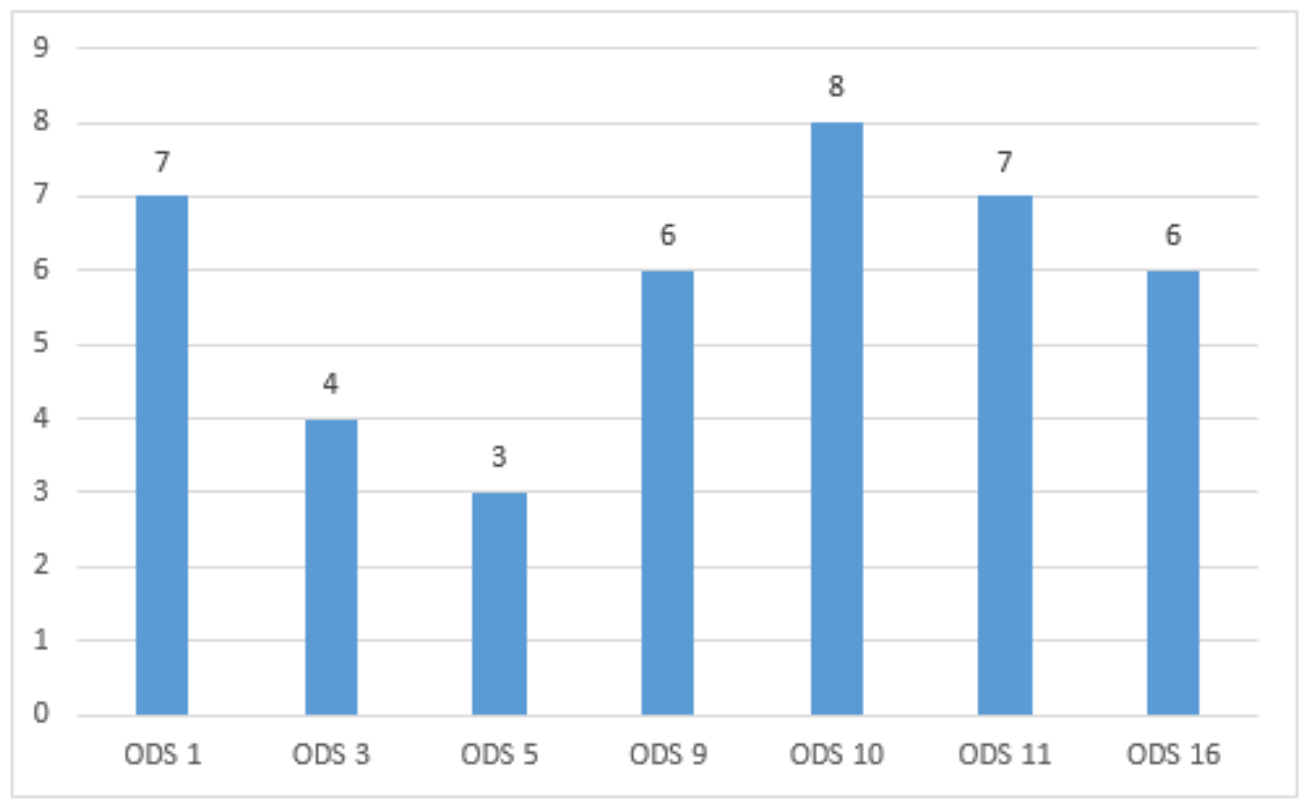

É possível perceber que o ODS 10, na qual promove a redução das desigualdades, contempla em $100 \%$ das Medidas de Resposta , e que tanto o ODS 1, que aborda a erradicação da pobreza, quanto - ODS 11, que refere-se a cidades e comunidades sustentáveis, contempla $87,5 \%$ das diretrizes propostas pelo plano de contingenciamento.

No entanto, o ODS 9, que atende a indústria, inovação e infraestrutura, e o ODS 16, que considera a paz, justiça e instituições fortes, apontam com $75 \%$ em consonância com as Medidas de Resposta. 
Enfim, o ODS 3, na qual se refere a boa saúde e bem-estar, e o ODS 5, que aborda a igualdade de gênero, são os Objetivos que tiveram menor concordância com as Medidas de Resposta com $50 \%$ e $37,5 \%$, respectivamente.

\section{DISCUSSÃO}

O planejamento determina um conjunto de ações, ou procedimentos, com vistas à execução de determinado projeto. Nesse sentido, deve pressupor um diagnóstico em que se apresentam as potencialidades e os problemas para que, então, sejam propostas as alternativas e soluções (PRIETO, 2005). Por conseguinte, todos esses elementos são fundamentais para se viabilizar um planejamento que promova a implementação de cidades saudáveis, que são aquelas que apresentam políticas amplas e soluções de planejamento para problemas urbanos de saúde. Uma política de informação em saúde ambiental é uma ferramenta essencial para a tomada de decisão e elaboração de políticas públicas visando à saúde e ao desenvolvimento sustentável (SOUZA et al., 2009).

É preciso articular os governos locais no desenvolvimento da saúde, a partir de um processo que envolva não apenas compromisso político, mas também ações concretas e mudanças institucionais, por meio de parcerias. Assim, considera-se saudável uma cidade ou município em que seus dirigentes municipais enfatizam a saúde de seus cidadãos dentro de uma ótica ampliada de qualidade de vida (RUMEL et al., 2005).

Desta forma, compreende-se que, durante um período de pandemia, as pessoas deixam de estar em risco, ou seja, encontram-se em situação de vulnerabilidade, pois a doença avança para um cenário onde está presente nos lugares, em escala global.

No âmbito mundial, a Organização Mundial da Saúde (OMS) orientou os países a adotarem medidas de isolamento social. No entanto, nem todos os países seguiram as recomendações, e consequentemente enfrentaram um agravamento do quadro epidêmico. Por questões políticopartidárias, diversas lideranças argumentaram que era preciso adotar medidas menos restritivas, com seus discursos direcionados às questões econômicas. No caso do Brasil, o governo federal divergiu com relação às recomendações do seu MS, o que resultou na demissão do ministro, conforme anunciado em BRASIL $(2020, \mathrm{~s} / \mathrm{p})$, que estava trabalhando em consonância com as diretrizes estabelecidas pela OMS.

Nesse contexto, evidenciam-se os conflitos de interesse entre as esferas municipais, estaduais e federal, o que mostra a importância de medidas que fortaleçam o Estatuto das Cidades. Assim, foram diagnosticadas as ações emergenciais propostas no planejamento emergencial desenvolvido pelo MS, com vistas a compreender de que forma estes indicadores podem fazer com que, tanto as pessoas como a própria cidade, fiquem menos vulneráveis a endemias, epidemias e, no cenário atual, a pandemias.

Apesar das diferentes épocas em que as referidas doenças ocorreram, é possível traçar similitudes entre os casos pandêmicos, no que diz respeito à imunidade das pessoas. Na sociedade contemporânea, é facilitada a transmissão dos vírus, devido ao contexto globalizado. Por isso, o distanciamento social se mostra uma das medidas mais eficazes.

$\mathrm{O}$ isolamento trata-se de uma estratégia semelhante à utilizada nas pandemias do passado, necessária por não haver vacina contra o vírus Sars-CoV-2, que tem alta transmissibilidade e taxa de letalidade superior às gripes sazonais. Medidas como a quarentena, a diminuição do fluxo de pessoas entre as cidades, e em alguns casos o lockdown, que permitem a entrada de mercadorias e o deslocamento dos profissionais de saúde, mas limitam o tráfego de pessoas que podem estar contaminadas por este vírus.

Devido ao adoecimento em massa da população, o número de óbitos evidencia a falência do sistema de saúde nos mais diversos países, incluindo sistemas robustos, como o do Reino Unido. Deste modo, é preciso refletir a respeito do desmonte e sucateamento do Sistema Único de Saúde (SUS) brasileiro, que ocorre devido à destinação de recursos, pelo governo atual, à iniciativa privada. Este modelo, espelhado no dos Estados Unidos, que não possui sistema público de saúde, e contabiliza hoje o maior número de mortes pela Covid-19. Estudos futuros podem relacionar esses dois fatores: o maior impacto da pandemia neste país e a ausência de um sistema de saúde que seja público. 
Com relação à economia mundial, há projeções para redução do Produto Interno Bruto (PIB) em diversos países. Nesse sentido, não há muito o que possa ser feito, apesar dos esforços governamentais com viés econômico. Sem distanciamento social, as projeções das autoridades de saúde apontam para um número muito maior de mortes dos empregados, dos empresários e, consequentemente, dos profissionais de saúde.

Alguns países, como Espanha, Estados Unidos, França, Inglaterra e Itália, que reativaram as atividades comerciais por negligência sobre o potencial pandêmico, só retornaram às medidas propostas pela OMS quando o número de óbitos superou a quantidade de lugares disponíveis nos cemitérios, e quando não havia mais leitos de Unidade de Terapia Intensiva (UTI).

No Brasil, este cenário já ocorre nas cidades de Fortaleza, Manaus e Rio de Janeiro. Estes municípios foram afetados de forma drástica, com a falência de cidadãos em suas próprias residências, devido à precariedade dos serviços de saúde. Por isso, estão sendo retomadas as medidas restritivas com maior rigidez, fazendo inclusive o uso da medida de lockdown, que foi adotada a princípio no município de São Luís do Maranhão.

Os países que foram acometidos tardiamente pela pandemia, entre eles o Brasil, têm a possibilidade (e o dever) de aprender com os erros e acertos dos primeiros países afetados. A OMS produz um catálogo de experiências, com recomendações e orientações das autoridades sanitárias, baseadas na ciência.

Neste ponto, é preciso esclarecer que ciência e fé não são conceitos antagônicos. É possível ter fé e seguir os avanços científicos. Quando o governo federal contraria as orientações da OMS, adota medidas contrárias à ciência que podem, efetivamente, aumentar o número de adoecimentos e de óbitos. Os protocolos indicados pelas autoridades sanitárias apontam para o isolamento social.

O discurso governamental brasileiro tangencia a aflição dos comerciantes e a tentativa de aliviar a pressão econômica, o que gera uma urgência na reabertura do comércio antes do prazo previsto, que pode dar fim à vida de várias pessoas. Argumenta-se que, após a pandemia da Covid-19, seria bom para as pessoas que a rotina voltasse ao normal, mas é preciso destacar que essa normalidade já não era suficiente para a maioria das pessoas.

A pandemia colocou em evidência que milhares de pessoas vivem e morrem na miséria. São pessoas que estão sendo socorridas pelo auxílio emergencial, mas que após esse período voltarão à condição de carência e de miséria. Fazem parte do grupo que se encontra em vulnerabilidade social. Sua normalidade é invisível e sem assistência, promovido pela desigualdade social.

Outra normalidade no Brasil é a política do Estado Mínimo. A dispersão do vírus Sars-CoV-2 em território nacional destacou a fragilidade do SUS, que deveria estar melhor equipado. O Estado também deveria estar mais preparado para socorrer os municípios, as empresas e a população. Com a estratégia de privatização dos serviços de saúde, segurança e educação, a maioria da população não terá condições para custeá-los.

Nesta lógica, quando a situação retornar à condição considerada dentro da normalidade, isso significa que as pessoas também voltarão a essa condição de vulnerabilidade social e de invisibilidade, por meio da qual não há preocupação do Estado nem da sociedade.

Quando se pensa em saúde pública, é preciso pensar em uma saúde única, que relaciona a humana, a animal e a ambiental. Quando há um desequilíbrio, a saúde como um todo estará ameaçada. As pandemias corroboram com este raciocínio, pois os vírus que estão nos animais são transmitidos para os seres humanos. Isso ocorre por causa da degradação e pressão sobre os ambientes naturais. Ao propor uma saúde única, é preciso pensar em proteger o meio ambiente, ou seja, pensar na economia com proteção da fauna, da flora e das pessoas.

É preciso promover uma melhor distribuição dos recursos, ao invés de uma maior taxa de produção. As pessoas que possuem baixa renda são, as mais afetadas por uma pandemia, seja pela carência ou pela dificuldade de acesso ao sistema de saúde. Uma nova normalidade deve ser criada porque o dito normal seria voltar ao contexto de vida em que não há preocupação com o meio ambiente, nem com a maioria das pessoas vulneráveis. Portanto, torna-se necessário pensar em uma sociedade mais humana, mais solidária, em que ocorra equidade na distribuição dessas riquezas. 


\section{CONSIDERAÇÕES FINAIS}

Diversas doenças fatais podem ser evitadas a partir da higienização das mãos, ou se o paciente tivesse chegado à unidade de saúde quando foram percebidos os primeiros sintomas. Por um lado, o pronto atendimento não está acessível a todos os cidadãos, sendo que em diversos lugares os serviços são inexistentes. Além disso, no senso comum, as pessoas acreditam que se trata apenas de uma "simples" gripe, e tragicamente acabam falecendo. Isso ocorre porque, na visão de Ramos, Lima e Silva (2018, p.165), condicionantes e determinantes de saúde são todos os fatores físicos, biológicos, sociais, culturais, econômicos e comportamentais que influenciam a saúde.

Quando surge uma variante para novas viroses, há uma ameaça existencial para a espécie humana. Nesse sentido, em busca de estratégias que sejam eficazes contra quaisquer vírus da gripe, o olhar científico foi direcionado à gestão pública municipal, com foco na pandemia gerada pela doença Covid-19.

A partir de uma revisão bibliográfica sobre o tema, seguida da análise das diretrizes propostas pelo MS para o Plano de Contingência Nacional para Infecção Humana pelo novo Coronavírus, utilizou-se o PCS para a sua instrumentalização, elencando os indicadores contidos no Eixo "Equidade, Justiça Social e Cultura de Paz" e relacionando-os com os ODS das Nações Unidas.

O programa disponibiliza 260 indicadores para implantação de uma cidade sustentável. 0 eixo temático escolhido para o trabalho contempla 43 desses indicadores, sendo que $58,13 \%$ desses podem ser utilizados para monitoramento das diretrizes contidas no planejamento.

Compreende-se que a adoção de indicadores de sustentabilidade no planejamento pode ser uma forma capaz de minimizar a vulnerabilidade das pessoas e dos lugares. No entanto, as cidades brasileiras evidenciaram suas fragilidades, devido aos desafios impostos pela gestão territorial em países em desenvolvimento. Ainda é preciso, portanto, avançar nas discussões e evidências. Até o momento, o que se sabe é que o distanciamento social é a única forma de evitar o contágio e ser capaz de achatar a curva de contaminação.

\section{REFERÊNCIAS}

AMAZONAS. Coronavírus: Situação Epidemiológica de COVID-19 e da Síndrome Respiratória Aguda Grave no Estado do Amazonas. Fundação de Vigilância em Saúde do Amazonas. Boletim Epidemiológico, ano 1, $\mathrm{n}^{\circ} 7,2020$.

BARDIN, L. Análise de conteúdo. São Paulo: Edições 70, 2011. p. 229.

BRASIL. Decreto, de 16 de abril de 2020. Atos do Poder Executivo. Diário Oficial da União: edição: 73 - A, seção 2 - Extra, Brasília, DF, p. 1, 2020.

BRASIL. Senado Federal. Valor-notícia. Manual de Comunicação da Secom, 2020. Disponível em: <https://www12.senado.leg.br/manualdecomunicacao/glossario/valor-noticia>. Acesso em: 30 abr. 2020

BRASIL. Painel Coronavírus, 2020. Disponível em: <https://covid.saude.gov.br/>. Acesso em: 10 maio 2020

\section{BRASIL. Plano de Plano de Contingência Nacional para Infecção Humana pelo novo}

Coronavírus COVID-19, 2020. Disponível em:

$<$ https://portalarquivos2.saude.gov.br/images/pdf/2020/fevereiro/13/plano-contingencia-coronavirusCOVID19.pdf>. Acesso em: 10 abr. 2020

GONZAGA, E. RIBEIRO, L. Desenvolvimento Humano e Sustentável para Área de Assentamento Urbano em Uberlândia. In: MOURA, C. et al. Direitos humanos: da legalidade à efetivação. Uberlândia: Composer, 2017. p. 201-2015

IBGE - FUNDAÇÃO INSTITUTO BRASILEIRO DE GEOGRAFIA E ESTATÍSTICA. Cidades e Estados, 2020. Disponível em: <https://www.ibge.gov.br/cidades-e-estados>. Acesso em: 20 abr. 2020. 
MARICATO, E. Metrópoles desgovernadas. Estudos avançados, v. 25, n. 71, 2011. p. 7-22.

PCS. Guia de referências para produção de indicadores e para metas de sustentabilidade urbana, 2019. Disponível em: <https://www.cidadessustentaveis.org.br/assets/pdf/Referencias-paraindicad ores-e-metas_PCS-CEBRAP_2019.pdf>. Acesso em: 25 abr. 2020.

https://doi.org/10.1590/S0103-40142011000100002

PCS. Programa Cidades Sustentáveis, 2017. Disponível em:

$<$ https://www.cidadessustentaveis.org.br/arquivos/Plano-de-

Metas/user_1042_programa_metas_planejamento_cidades_sustentaveis_2017.pdf>. Acesso em: 28 abr. 2020.

PRIETO, E. C. Os Desafios Institucionais e Municipais para implantação de uma cidade universitária: o Câmpus Glória da Universidade Federal de Uberlândia. Dissertação (Mestrado) — Universidade Federal de Uberlândia, Uberlândia, 2005.

RAMOS, J. D.; LIMA, S. C.; SILVA, J. J. O perfil epidemiológico da população do Chamanculo C. In: LIMA, S. C.; RAMOS, J. D.; MENDES, P. C. (Orgs.). Saúde ambiental, território e promoção da saúde em Maputo, Moçambique. Uberlândia: Editora Assis, 2018. p. 165-176.

ONU. Organização das Nações Unidas. Transformando Nosso Mundo: A Agenda 2030. 2015.

Disponivel em: <http://www.itamaraty.gov.br/images/ed_desenvsust/Agenda2030-completo-site.pdf>. Acesso em: 25 abr. 2020

RUMEL, D.; SISSON, M.; PATRÍCIO, Z. M.; MORENO, C. R. C. Cidade saudável: relato de experiência na coleta e disseminação de informação sobre determinantes de saúde. Saúde e Sociedade, v. 14, 2005. p. 134-143. https://doi.org/10.1590/S0104-12902005000300009

SOUZA, J. H.; PAULELLA, E. D.; TACHIZAWA, T.; POZO, H. Desenvolvimento de indicadores síntese para o desempenho ambiental. Saúde e Sociedade, v. 18, 2009. p. 500-514. https://doi.org/10.1590/S0104-12902009000300014

TRAQUINA, Nelson. Teorias do Jornalismo, Volume II: A tribo jornalística - uma comunidade interpretativa transnacional, 2. ed. Florianópolis: Insular, 2008. p.208.

TRADINGVIEW. Coronavírus (COVID-19) gráficos e estatísticas. Disponível em: <https://br.tradingview.com/covid19/> Acesso em: 10 mar. 2020.

UFU. Nota do Comitê de Monitoramento à Covid-19 - UFU. 2020. Disponível em: <http://www.comunica.ufu.br/noticia/2020/04/nota-do-comite-de-monitoramento-covid-19-ufu>. Acesso em: 29 abril. 2020

WOLF, Mauro. Teorias da comunicação de massa. São Paulo: Martins Fontes, 2003. p.312. 